\title{
Should COVID-19 Concern Nephrologists? Why and to What Extent? The Emerging Impasse of Angiotensin Blockade
}

\author{
Luca Perico $^{a} \quad$ Ariela Benignia $^{a}$ Giuseppe Remuzzia, b \\ astituto di Ricerche Farmacologiche Mario Negri IRCCS, Centro Anna Maria Astori, Science and Technology Park \\ Kilometro Rosso, Bergamo, Italy; ${ }^{b}$ Department of Biomedical and Clinical Sciences, University of Milan, Milan, Italy
}

\section{Keywords}

Severe acute respiratory syndrome coronavirus .

SARS-CoV-2 - COVID-19 • Renal and cardiac side effects .

Angiotensin-converting enzyme inhibitors · Angiotensin receptor blockers

\begin{abstract}
Here, we review the most recent findings on the effects of SARS-CoV-2 infection on kidney diseases, including acute kidney injury, and examine the potential effects of ARBs on the outcomes of patients with COVID-19. Lastly, we discuss the clinical management of COVID-19 patients with existing chronic renal disorders, particularly those in dialysis and with kidney transplants.

(c) 2020 S. Karger AG, Basel
\end{abstract}

\section{Introduction}

Coronaviruses are a group of pathogens that co-infect humans and other vertebrates. These viruses affect the respiratory, gastrointestinal, and central nervous systems, as well as livers, of humans, livestock, birds, bats, mice, and many other wild animals [1]. Among this class of viruses are the two known zoonotic coronaviruses that induced Severe Acute Respiratory Syndrome (SARS) and
Middle East Respiratory Syndrome (MERS) in 2003 and 2012, respectively [1].

Starting in December 2019, a cluster of unexplained pneumonia cases was reported in the city of Wuhan, the capital of Hubei province in central China. In January 2020 , the pathogen causing this bilateral interstitial pneumonia was identified through high-throughput sequencing of the viral RNA genome. The World Health Organization (WHO) named this new virus Severe Acute Respiratory Syndrome Coronavirus 2 (SARS-COV-2), which belongs to the $\beta$-coronavirus cluster, which also comprises the viruses causing SARS and MERS [2]. The consequent SARS-CoV-2-related disease was defined as coronavirus disease 2019 (COVID-19).

According to the earliest available data, the majority of patients diagnosed with COVID-19 before January 1, 2020, were linked to the Seafood Wholesale Market in Wuhan [3]. In the early stages, the incubation period was 5.2 days, with the epidemic size doubling every 7.4 days [3], thus suggesting a high human-to-human transmission rate. The person-to-person transmission routes included droplet inhalation transmission, direct transmission through coughing and sneezing, as well as contact transmission, including oral, nasal, and eye mucous membrane contacts.

Many of the most common symptoms are like those of the common seasonal flu and cold, and the WHO has de- karger@karger.com www.karger.com/nef

(c) 2020 S. Karger AG, Basel

Karger"
Giuseppe Remuzzi, MD

FRCP Istituto di Ricerche Farmacologiche Mario Negri IRCCS Centro Anna Maria Astori, Science and Technology Park Kilometro Rosso Via Stezzano 87, IT-24126 (Italy)

giuseppe.remuzzi@marionegri.it 
scribed fever and a dry cough as the most common symptoms of COVID-19, affecting almost 90 and $70 \%$ of infected subjects, respectively [4]. Additionally, $40 \%$ of COVID-19 patients suffer from fatigue and $18.6 \%$ experience dyspnoea, while nasal congestion, nausea and diarrhoea are seldom reported $[5,6]$.

\section{Epidemiology and Natural Course of COVID-19}

According to the WHO, SARS-CoV-2 infection reached pandemic proportions by March 15, 2020, with 153,517 laboratory-confirmed cases of COVID-19 in 143 different countries [7]. The majority of cases were reported in China $(81,048)$, with a gross mortality of $4 \%(3,204$ total deaths), although the true mortality rate may not have been estimated correctly [8]. Even if the Chinese outbreak is slowing and stabilizing, the total number of newly infected subjects outside of China is increasing significantly to 72,469 confirmed cases, with global mortality related to COVID-19 reaching 3.5\%, 2,531 deaths [7]. In particular, Europe is becoming the biggest disease outbreak after China with Italy leading the total number of COVID-19 cases (24,747 and 1,809 deaths), followed by Spain ( 7,844 cases), Germany (5,813 cases), and France (5,437 cases). Outside of Europe, Iran (13,938 cases) and South Korea ( 8,162 cases) reported the highest number of cases so far [7].

Despite the few epidemiological data available so far, early efforts have focussed on describing the clinical course of this disease and describing the most severe cases. According to the European Centre for Disease Prevention and Control (ECdC) [6], the evidence from analyses of cases to date is that COVID-19 infection causes mild disease, without pneumonia or with mild pneumonia, in about $80 \%$ of patients, most of whom recover spontaneously [6]. Conversely, $14 \%$ of infected patients experience a more severe form of the disease and $6 \%$ become critically ill [6]. The majority of severe cases and deaths occur among the elderly and those with underlying chronic conditions [6]. However, also younger patients can experience severe disease symptoms, requiring intensive care therapies. Considering that all the different age groups are equally susceptible to SARS-CoV-2 infections, it is of critical importance that also the youngest subjects, who may experience from milder to no symptoms, comply with the self-isolation procedures in order to prevent the virus diffusion. In this context, a recent paper estimated that $86 \%$ of all infections were undocumented, highlighting the importance of the identification of infected people and the tracking of all the closest contacts to implement quarantine procedure and limit the spread of the virus [9].

Given the evolving nature of the disease outbreak, solid epidemiological data on COVID-19 are still lacking. Li et al. [3] identified the median age of SARS-CoV-2-infected subjects as being 59 years, $56 \%$ of whom were male, and the average incubation period was 5.2 days. An additional study found that the median age of death was 75 years, with the median time from the first symptom to death being 14 days [10]. The median time from early symptoms to death in people aged 70 or older was shorter (11.5 days) than that in people under 70 years old (20 days), suggesting faster disease progression in the elderly [10].

In a small subset of subjects infected with SARS-CoV-2 ( $n=41)$, Huang et al. [11] confirmed male predominance in incidence (73\%), although with a lower median age of 49 years. They also found that $32 \%$ of COVID- 19 patients had underlying diseases, including diabetes, hypertension, and cardiovascular disease, while the fatality rate in these SARS-CoV-2-infected subject was 15\% [11]. These data were further corroborated in the largest Chinese study conducted so far, with over 40,000 confirmed COVID-19 cases, in which the overall case fatality rate (CFR) was $2.3 \%$ and hypertension (CFR 6.0\%), diabetes (CFR $7.3 \%$ ), cardiovascular disease (CFR 10.5\%) and age $>70$ (CFR 10.2\%) were the most frequently reported co-morbidities [5].

Although these data may provide some clues regarding the epidemiology of COVID-19, studies in such small laboratory-confirmed cases can be misleading, as only severe cases may be included, possibly skewing our understanding of the actual trajectory and impact of the COVID-19 outbreak [8]. As the epidemic evolves, public health activities and simultaneous surveillance studies will be required in order to elucidate the epidemiology of COVID-19 and predict its potential clinical impact.

\section{The Zoonotic Origin of SARS-CoV-2}

In order to understand the cross-species transmission of the novel coronavirus, several studies have tried to identify possible reservoirs of SARS-CoV-2 in animals. So far, the intermediate hosts of SARS-CoV-2 have been elusive, and potential candidates have included snakes, minks, and others [12]. However, Lu et al. [13] have documented that SARS-CoV-2 exhibited an $88 \%$ identity to two bat-derived SARS-like coronaviruses. Concomitant- 


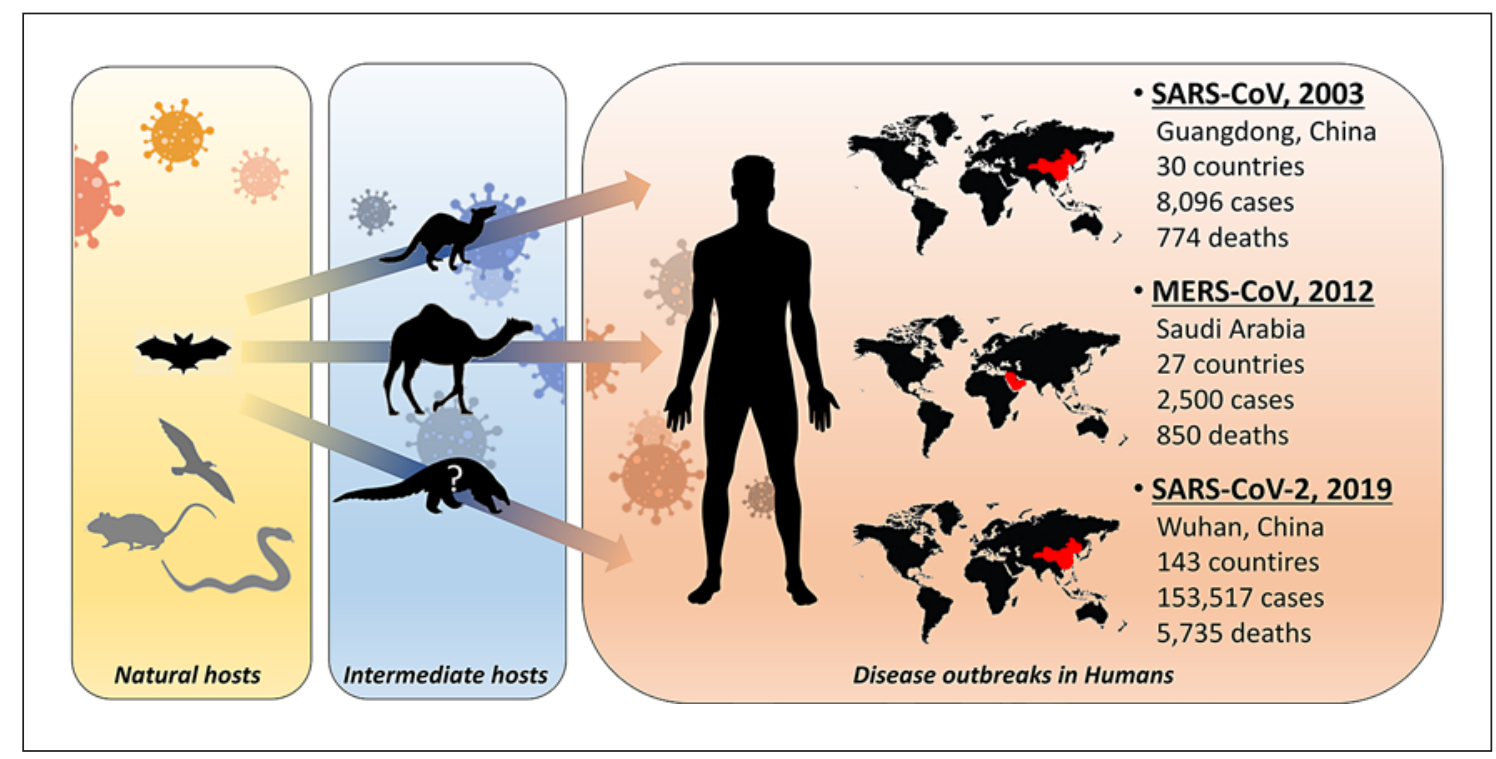

Fig. 1. The zoonotic origins of coronaviruses. In nature, several animal species act as natural host reservoirs for viruses. Coronaviruses are commonly found in different bat species. However, intermediate hosts are thought to be necessary for coronaviruses to move from the primary reservoir species into humans. Coronaviruses inducing the outbreak of Severe Acute Respiratory Syndrome (SARS-CoV) and Middle East Respiratory Syndrome (MERS-CoV) were originally bat viruses that spread to an intermediate animal (civet cat and camel, respectively), which then ex- posed humans to the viruses. Genetic analysis of the coronavirus causing the novel COVID-19 outbreak (SARS-CoV-2) recently showed that their closest genetic relatives appear to be bat coronaviruses, with the role of intermediate species possibly played by the pangolin, although with some conflicting results. Recent studies shown that some bat coronaviruses can infect human cells without passing through an intermediate host. Total number of COVID-19 cases and deaths are relative to the available data on March 15, 2020 . ly, the study by Ji et al. [12] showed that SARS-CoV-2 was a chimaeric virus constituted by a bat coronavirus and a coronavirus of unknown origin. In a similar vein, Zhou et al. [14] reported that the sequence similarity in the SARS-CoV-2 virus and the coronavirus isolated from Rhinolophus affinis is $96 \%$. Collectively, these data suggest that bats may be the actual source of SARS-CoV-2, which would also be in line with previous findings that showed that bats host several strains of coronavirus [15].

More recently, the mystery over the animal source of coronavirus deepened, as an analysis of 1,000 metagenomic samples suggested that pangolins may be an intermediate host for SARS-CoV-2 (Fig. 1). Indeed, 70\% of pangolins are positive for the coronavirus, which shares a $99 \%$ sequence similarity with the strain of SARS-CoV-2 currently infecting humans [16]. However, this result did not actually refer to the entire viral genome, but was related to a specific site known as the receptor-binding domain [16]. This finding was challenged by subsequent studies that showed that SARS-CoV-2 only shared between 85.5 and $92.4 \%$ of the pangolins' coronavirus [17]. Furthermore, the coronavirus carried by pangolins did not exhibit the same structural features as SARS-CoV-2 [18], ruling out the possibility that the recent outbreak of COVID-19 might come directly from pangolins.

\section{The Pathogenic Mechanisms of SARS-CoV-2 Infection}

Although the SARS-CoV-2 animal reservoir may remain unknown for a long time, what we have learned so far is that the genomic characterisation of SARS-CoV-2 revealed a significant phylogenetic distance from previously identified coronaviruses that caused human diseases, as it shared only 79 and $50 \%$ identity with SARS-CoV and MERS-CoV, respectively $[19,20]$.

Despite these differences, several studies have reported that SARS-CoV-2 exploits the same membrane-bound angiotensin-converting enzyme 2 (ACE2) as SARS-CoV to gain access to its target cells [21-23], although it has greater binding affinity [24]. ACE2 is a carboxypeptidase that preferentially removes carboxy-terminal hydrophobic or basic amino acids [25]. ACE2 cleaves a single resi- 
due from angiotensin I (Ang I), generating Ang 1-9, and a single residue from angiotensin II (Ang II) to generate Ang 1-7, whose vasodilator, anti-proliferative, and antifibrotic functional effects oppose those of the Ang II generated by angiotensin converting enzyme (ACE) [25].

A recent study showed that ACE2 is highly expressed in the mouth and tongue, facilitating viral entry in the host. In normal human lungs, ACE2 is expressed in lower lungs on type I and II alveolar epithelial cells. After infection, SARS-CoV-2 entry starts with the binding of the spike glycoprotein expressed on the viral envelope to ACE2 on the alveolar surface. The binding of SARSCoV-2 to ACE2 stimulates the clathrin-dependent endocytosis of the whole SARS-CoV-2 and ACE2 complex, inducing fusion at the cell membrane. Endosomal cell entry of SARS-CoV-2 is facilitated by a low $\mathrm{pH}$ and $\mathrm{pH}-$ dependent endosomal cysteine protease cathepsins [26]. Once inside the cells, SARS-CoV-2 exploits the endogenous transcriptional machinery of alveolar cells to replicate itself and spreads through the entire lung [26]. Given the critical role of endosomal acidic $\mathrm{pH}$ for SARS-CoV-2 processing and internalization, it has been suggested that the antimalarial drug chloroquine could exert a potent antiviral effect by virtue of its ability to increase endosomal pH [27]. Inside the cells, chloroquine becomes rapidly protonated and is concentrated in endosomes [27]. The positive charge of the chloroquine increases the organelle's $\mathrm{pH}$ with abrogation of virus-endosome fusion, ultimately inhibiting the infection [27]. In addition to chloroquine, hydroxychloroquine has been considered as a possible candidate for short-term treatment trials [27]. Furthermore, also amiodarone has been suggested as a possible inhibitor of SARS coronavirus spreading by its ability to interfere with the endocytic pathway [28].

When SARS-CoV-2 infects most of the ciliated cells in the alveoli, these cells stop carrying out their normal activity, which consists of clearing the airways, with a consequent progressive accumulation of debris and fluids in the lungs and acute respiratory distress syndrome (ARDS).

Because ACE2-binding affinity has been shown to be the major determinant in SARS-CoV-2 infectivity, experiments at the atomic resolution level of virus-receptor interaction have been carried out to identify the precise receptor-binding domain (RBD) of spike glycoprotein on the viral envelope that is involved in SARS-CoV-2 interaction with ACE2 [29]. In this study, the author found that the sequence of SARS-CoV-2 RBD is similar to that of SARS-CoV, further confirming the hypothesis that ACE2 is the entry receptor for SARS-CoV-2 [29]. Nota- bly, they also found that SARS-CoV-2 RBD harbours a single mutation that significantly enhances its binding affinity to ACE2, suggesting that SARS-CoV-2 may have evolved with an increased capability to infect and spread among humans [29]. The identification of the specific RBD of SARS-CoV-2 might provide us with a unique opportunity to develop targeted therapies to halt the interaction between SARS-CoV-2 and ACE2, as carefully described recently [30].

Although in its infancy, a recent study investigated the differences in ACE2 gene expression between individuals in relation to race, age, sex and smoking status, in order to identify possible disparities between patients that would result in increased COVID-19 susceptibility [31]. To this end, five large-scale bulk transcriptomic datasets of normal lung tissue and two single-cell transcriptomic datasets were investigated and showed that race (Asian vs. Caucasian), age (>60 vs. $<60$ ) and sex (male vs. female) did not correlate with significant disparities in ACE2 gene expression [31]. However, significantly higher ACE2 gene expression was found in former smokers' lungs compared to non-smokers' lungs, suggesting that smoking may be a risk factor for COVID-19 susceptibility [31].

\section{The Contribution of ACE2-Expressing Organs in SARS-CoV-2 Replication and Infectivity}

In addition to the alveolar cells in the lungs, ACE2 expression has been reported in other organs, including the kidney, the heart and the gut [25]. Whether robust ACE2 expression in these organs affects SARS-CoV-2 infectivity remains ill-defined. The finding that acute kidney injury (AKI), cardiac damage and abdominal pain are the most commonly reported co-morbidities of COVID-19 $[31,43]$ suggests that SARS-CoV-2 may have a tropism for these organs. However, whether SARS-CoV-2 replication actually occurs in these organs, possibly affecting their functional homeostasis and contributing to the virus spreading throughout the body, remains a matter of intense debate.

It has been reported that in the kidney, ACE2 is highly expressed in the brush border of proximal tubular cells and, to a lesser extent, in podocytes, but not in glomerular endothelial and mesangial cells [25]. In earlier studies during the SARS outbreak in 2003, it was found that only $6 \%$ of SARS-CoV-infected subjects experienced AKI [32]. Although it was a relatively uncommon feature of the disease, AKI was identified as a fatal complication of SARS, given that almost $92 \%$ of SARS patients with AKI died 
[32]. In order to evaluate whether AKI was induced by active SARS-CoV replication in tubular cells that express high levels of ACE2, Lai and colleagues [32] investigated the presence of SARS-CoV viral particles using electron transmission microscopy in renal specimens from postmortem SARS patients with AKI. They found that SARS$\mathrm{CoV}$ was not detectable in any of the analysed patients and suggested that renal impairment was likely related to multi-organ failure [32]. They further suggested that AKI in SARS patients could be the result of specific pathogenic conditions, including cytokine release syndrome [33], rather than active viral replication in the kidney. Indeed, increasing viral infection in alveolar cells results in massive recruitment of immune cells, which produce large amount of cytokines, causing multiple-organ failure. That this might actually be the case in SARS-CoV infection was discovered by a subsequent study that showed that an interferon-gamma-related cytokine storm was induced post-SARS-CoV, leading to severe organ damage in SARS patients [34]. This process is not new to nephrologists, as cytokine-mediated inflammatory AKI has been reported in several clinical conditions, such as treatment with immune-checkpoint inhibitors and chimaeric antigen receptor (CAR) T cells in cancer patients [35], as well as thymoglobulin treatment in renal transplanted patients [36].

As for the novel coronavirus, a recent study reported that the human kidney is a specific target for SARS-CoV-2 infection [37]. Diao and colleagues [37, 38] examined the viral nucleocapsid protein in situ in the kidney post-mortem and found that SARS-CoV-2 antigens accumulated in kidney tubules, suggesting that SARS-CoV-2 infects the human kidney directly, inducing AKI and contributing to viral spreading in the body. The difference between the higher renal tropism of SARS-CoV-2 versus SARS$\mathrm{CoV}$ could be explained by the increased affinity of SARSCoV-2 for ACE2, allowing greater infection of the kidney, which may act as a viral reservoir [29].

Additional studies in small subsets of COVID-19 patients, revealed that proteinuria and haematuria are common features found in almost $40 \%$ of patients on hospital admission [39]. CT scan of the kidneys showed reduced density, suggestive of inflammation and oedema [40]. Furthermore, subjects infected with SARS-CoV-2 seem to be affected by AKI more frequently than subjects infected with SARS-CoV [39]. A very recent study by Yao et al. [69] (published online ahead of print) confirms that SARS-CoV-2 infection, in addition to the lungs, damages vessels, kidney and other organs. Hyaline thrombi are found in small vessels in different organs. It would be of outmost importance to investigae in depth pathological changes in atopsy material.

Whether cytokine release syndrome is also a feature of SARS-CoV-2 infection leading to AKI as in SARS, is not known. What has been shown so far is that a specific inhibitor of interleukin 6 (IL-6), the major driver of cytokine release syndrome, appears to be beneficial in severe COVID-19 cases [41]. This drug, Tocilizumab, has been approved by the US Food and Drug Administration (FDA) for the treatment of rheumatoid arthritis and is now under investigation in a randomized, controlled trial (ChiCTR2000029765) in China, involving 188 patients with COVID-19 [41]. The results of this study are much anticipated and expected to fully clarify the therapeutic potential of Tocilizumab, although there are still some concerns regarding the cardiovascular safety and cancer risk associated with this drug [42].

In the heart, ACE2 localizes in cardiac endothelial cells, the smooth muscle cells of myocardial vessels, as well as in cardiac myocytes [43]. It has been reported that SARS-CoV viral RNA was detected in 35\% of autopsied human heart samples from patients with SARS [44]. In addition, SARS-CoV was able to mediate myocardial inflammation and damage associated with the down-regulation of the myocardial ACE2 system, which may be responsible for myocardial dysfunction and adverse cardiac outcomes in patients with SARS [44]. To date, no data are available to assess the actual role of the heart in SARSCoV-2 replication. However, considering that SARSCoV-2 uses human ACE2 more efficiently than SARS$\mathrm{CoV}$, it is conceivable that cardiac replication of SARSCoV-2 may be an important determinant for COVID-19 prognosis [45], as has been described for the kidney.

Lastly, ACE2 has been localized also in enterocytes in the gut, where it maintains proper cellular function through the regulation of inflammation [46, 47]. The clinical relevance of the possible replication of SARSCoV-2 within enterocytes was recently brought to light by a study that suggested that, as with other coronaviruses, SARS-CoV-2 may be found in faecal excretions, with obvious implications for human transmission [47].

\section{The Paradoxical Effect of ACE2 Modulation in the Outcome of Coronavirus Infections}

From what we have learned from epidemiological data, over two-thirds of patients who died from COVID-19 had diabetes or cardiovascular disease [48]. Most patients affected by these diseases are treated with angio- 
tensin-receptor blockers (ARBs) as first-line therapy. Several studies have shown that ARBs are able to increase ACE2 expression in the kidney and the heart very substantially (2- to 5-fold) [49-52]. Although there is no direct evidence for the lungs, it is most likely that ARBs can increase ACE also in alveolar cells. One might wonder whether the use of these drugs could predispose patients to increased SARS-CoV-2 infection and more severe illness [53].

The answer to this question is not as simple as it seems, at least based on current knowledge. Preclinical studies have documented that ACE2 is significantly downregulated in different animal models of severe lung injury [54, 55]. Additionally, it has been shown that the pharmacological inhibition of the Ang Type 1 receptor (AT1R) by losartan attenuated severe acute lung injury in mice injected with the spike glycoprotein of SARS-CoV [56]. This counter-intuitive finding is strongly supported by a study in experimental models showing that ACE2 blockade or genetic manipulation to delete Ace 2 resulted in exacerbated lung damage and reduced animal survival after respiratory syncytial virus infection [57]. Altogether, the above complementary approaches suggest that ACE2 is protective in lung injury during coronavirus infection. Assuming that these circumstances are correct, how can we explain that ACE2 upregulation by $\mathrm{ARBs}$ is protective during SARS-CoV-2 infection?

First, SARS-CoV-2 entry into target cells is a tightly regulated multi-step processes, of which binding to ACE2 is merely the first. Indeed, TMPRSS2 is an essential serine protease required for spike glycoprotein priming after binding to ACE2 $[20,45,46]$. Increased expression of ACE2 by ARBs could induce the sequestration of SARS-CoV-2 on the cell membrane that, however, might not be paralleled by an increase in TMPRSS2, thus ultimately limiting viral infection. Whether this is the case, the TMPRSS2 inhibitor, camostat mesylate, which has been approved for some forms of cancer and hepatitis, might be a valuable treatment option for blocking multiple SARS-CoV-2 entry routes [21]. Additionally, membrane-bound ACE2 is processed by the metalloproteinase ADAM17, which cleaves the ACE2 ectodomain that can be released in soluble form. Even though ARBs can increase ACE2 expression in the lungs, we do not know whether this also results in an increased shedding rate of ACE2, with a consequent increase in soluble ACE2 that would act as a decoy receptor that buffers circulating SARS-CoV-2 and limits viral entrance in target cells. What has been shown so far is that the administration of recombinant ACE2 has beneficial effects following respi- ratory syncytial virus infection in mice [57]. Whether this could be a valuable tool for COVID-19 patients will become clear from the open label, randomized, controlled, pilot clinical study (ClinicalTrials.gov Identifier: NCT04287686) that is ongoing to assess the specific therapeutic value of recombinant human ACE2 administration in COVID-19 patients.

Second, ARBs enable the increase of available Ang II by competing with the same AT1R. The increased levels of Ang II become available substrates for ACE2. Engagement of the catalytic domain of ACE2 by its substrates can induce a large conformational change in the threedimensional structure of this receptor [58]. Even though SARS-CoV2 spike glycoprotein recognizes a site of ACE2 that is different from the catalytic domain, it is conceivable that the increased binding of Ang II to the catalytic domain could induce a structural change in ACE2 that is unfavourable for SARS-CoV-2 binding and internalization. Additionally, the generation of Ang 1-7 from Ang II by ACE2 can create a cytoprotective environment within the lungs that may counterbalance vasoconstriction and profibrotic processes, a key protective mechanism during coronavirus infection [56], consistent with the protective role of ACE2 in acute lung injury $[59,60]$.

All these scenarios tend to suggest that ACE2 in the lungs may play a protective role in SARS-CoV-2 infection. These considerations should limit the great concern thar arose among the nephrology community regarding whether or not discontinuing ARBs in COVID-19 patients with diabetes and hypertension. Additionally, the official statements by the European Society of Hypertension (ESH) and the European Society of Cardiology (ESC) recommend that treatment with ARBs should be as conservative as possible in patients at risk for COVID-19 or in those already diagnosed with COVID-19 [61, 62].

From previous studies during the Ebola outbreak in Sierra Leone, it has been reported that treatment with ARBs greatly improved the survival of approximately 100 infected patients [63]. Additionally, ARBs also associated with decreased mortality in patients with pneumonia [60]. In this context, there is another very important, recent observation that ACE2 receptor abundance decreases in the elderly in all tissues, counterintuitively placing them at a greater risk of severe illness. According to these studies, large-scale, prospective studies will be required to evaluate whether inexpensive and widely available ARBs may have a therapeutic potential also in COVID-19 patients [64]. 


\section{What Should We Do for Patients with End-Stage Renal Disease and Transplant?}

Although the available epidemiological data have confirmed that $\mathrm{AKI}$ is one of the main risk factors in the prognosis of COVID-19 and diabetes as the main renal comorbidity, the potential impact of COVID-19 on patients affected by other renal conditions, such as end-stage renal disease and transplantation, is still not clear at this phase of the pandemic.

Given the high rate of SARS-CoV-2 infection in hospitalized patients, COVID-19 presents particular challenges for patients on dialysis. What we know so far for haemodialysis patients derives from observations from a study that reviewed the course of the disease outbreak in a single haemodialysis centre in Renmin Hospital in Wuhan University [65]. From January 14, 2020, to February 17,2020 , there were a total of 37 cases of COVID-19 among 230 haemodialysis patients and 4 cases in a staff of 33. In most patients, the COVID-19 symptoms were mild, with no patients admitted to intensive care units. During the epidemic, 7 haemodialysis patients died, including 6 with COVID-19 and 1 without COVID-19. The causes of death were apparently not related to pneumonia. Analysis of peripheral blood samples from haemodialysis patients infected with SARS-CoV-2 showed a remarkable reduction in the numbers of $\mathrm{T}$ cells, $\mathrm{T}$ helper cells, killer $\mathrm{T}$ cells, and NK cells in PBMCs, as well as lower serum levels of inflammatory cytokines, compared to non-haemodialysis patients with COVID-19. Collectively, this study reported that haemodialysis patients with COVID-19 are likely to experience mild disease that does not develop into full-blown pneumonia, probably due to the reduced function of the immune system and decreased cytokine storms. However, this report also suggests that haemodialysis patients are at high risk of being infected with SARS-CoV-2 and additional prevention measures are essential in managing the epidemic in haemodialysis centres.

In line with this consideration, the Centers for Disease Control and Prevention (CDC) have recently released COVID-19 interim guidance for outpatient haemodialysis facilities [66]. For providers of dialysis services, the priority is the early recognition and isolation of individuals with respiratory infection, patient placement, and the use of personal protective equipment. Additionally, as in all healthcare settings, the use of N95 respirators and other respiratory protection devices during high-risk procedures is the highest priority, while still protecting healthcare personnel with face masks and eye shields during other routine patient care activities in the setting of temporary respirator shortages. More detailed guidelines for managing COVID-19 outbreaks in dialysis units have also recently been developed by the Chinese Society of Nephrology and the Taiwan Society of Nephrology [67].

Currently, there are no specific data on the impact of SARS-CoV-2 infection in patients with generalized immunosuppression and transplantation. For this reason, the proper management of patients with kidney transplants diagnosed with COVID-19 is still being evaluated. For patients in home quarantine, therapy with Levofloxacin, rather than Azithromycin, is recommended after careful evaluation by the physician. In this case, empirical reduction of cyclosporine should be performed. Adequate hydration and the use of paracetamol are suggested in case of fever. For hospitalized patients, the use of steroids is controversial. During the SARS-CoV infection in 2003, the WHO recommended avoiding the use of steroids, due their potential inhibition of viral clearance and prolongation of the duration of viremia. However, whether this is also the case for SARS-CoV-2 is currently unknown. For this reason, we suggest maintaining the most conservative measures possible regarding the use of steroids.

In some instance, it has been suggested that cyclosporine, tacrolimus, everolimus, and sirolimus can be discontinued and replaced with the protease inhibitors Lopinavir/Ritonavir. This drug has been proposed as supportive, off-label therapy in COVID-19 patients but cannot be taken in combination with immunosuppressants due to strong drug interactions. However, the therapeutic efficacy of Lopinavir/Ritonavir has never been confirmed and its therapeutic potential is still under investigation in an ongoing Chinese clinical trial (ChiCTR2000029308). This drug is a protease inhibitor that specifically blocks the retroviral aspartyl protease (retropepsin), an enzyme involved in peptide bond hydrolysis in retroviruses that is essential for processing the gag and gag-pol polyproteins during HIV virion maturation [68]. Given the high specificity of Lopinavir/Ritonavir against viral HIV protease, the exact mechanism through which these drugs may exert their protective function in COVID-19 has never been reported. Given the lack of solid proof for the efficacy of Lopinavir/Ritonavir, we strongly discourage administration of Lopinavir/Ritonavir instead of immunosuppressants as the limited benefit of this protease inhibitor is not worth the risk of allograft rejection.

Finally, the risk of acquiring COVID-19 from organ donation is low. However, it has been shown that SARS$\mathrm{CoV}-2$ has a high tropism for the kidney, where it has been 
shown to replicate in almost $30 \%$ of COVID-19 patients $[37,38]$. For this reason, screening for COVID-19 in kidney donors should be an important issue. Additionally, living donors who show symptoms or have travelled in highrisk areas should generally be asked to postpone donation for 14-28 days. Information about recent travel and possible exposure should also be considered in deceased donors in order to determine the safety of organ donation.

\section{Acknowledgment}

Luca Perico is recipient of the Career Development Award from Fondazione Aiuti per la Ricerca sulle Malattie Rare (ARMR), Bergamo, Italy.

\section{Disclosure Statement}

The authors have no conflicts of interest to declare.

\section{References}

$1 \mathrm{Xu} \mathrm{J}$, Zhao S, Teng T, Abdalla AE, Zhu W, Xie $\mathrm{L}$, et al. Systematic comparison of two animalto-human transmitted human coronaviruses: SARS-CoV-2 and SARS-CoV. Viruses. 2020 Feb;12(2):244.

2 Sun P, Lu X, Xu C, Sun W, Pan B. Understanding of COVID-19 based on current evidence. J Med Virol. doi: 10.1002/jmv.25722.

3 Li Q, Guan X, Wu P, Wang X, Zhou L, Tong $\mathrm{Y}$, et al. Early transmission dynamics in $\mathrm{Wu}-$ han, China, of novel coronavirus-infected pneumonia. N Engl J Med. 2020 Jan. doi: 10.1056/NEJMoa2001316.

4 Report of the WHO-China Joint Mission on Coronavirus Disease 2019 (COVID-19) [cited 2020 Mar 10]. Available from: https:// www.who.int/docs/default-source/coronaviruse/who-china-joint-mission-on-covid19-final-report.pdf.

5 Roser M, Ritchie H. Coronavirus Disease (COVID-19). Our World in Data. 2020 [cited 2020 Mar 10]. Available from: https://ourworldindata.org/coronavirus.

6 Guan WJ, Ni ZY, Hu Y, Liang WH, Ou CQ, $\mathrm{He}$ JX, et al. Clinical characteristics of coronavirus disease 2019 in China. N Engl J Med. 2020 Feb.

7 Situation Report - 55 [cited 2020 Mar 16]. Available from: https://www.who.int/docs/ default-source/coronaviruse/situation-reports/ 20200315-sitrep-55-covid -19 .pdf? sfvrsn= 33daa5cb_6.

8 Lipsitch $\bar{M}$, Swerdlow DL, Finelli L. Defining the epidemiology of covid-19 - studies needed. N Engl J Med. 2020 Feb.

9 Li R, Pei S, Chen B, Song Y, Zhang T, Yang W, et al. Substantial undocumented infection facilitates the rapid dissemination of novel coronavirus (SARS-CoV2). Science. 2020 Mar.

10 Wang W, Tang J, Wei F. Updated understanding of the outbreak of 2019 novel coronavirus (2019-nCoV) in Wuhan, China. J Med Virol. 2020 Apr;92(4):441-7.

11 Huang C, Wang Y, Li X, Ren L, Zhao J, Hu Y, et al. Clinical features of patients infected with 2019 novel coronavirus in Wuhan, China. Lancet. 2020 15;395(10223):497-506.

12 Ji W, Wang W, Zhao X, Zai J, Li X. Crossspecies transmission of the newly identified coronavirus 2019-nCoV. J Med Virol. 2020; 92(4):433-40.
13 Lu R, Zhao X, Li J, Niu P, Yang B, Wu H, et al. Genomic characterisation and epidemiology of 2019 novel coronavirus: implications for virus origins and receptor binding. Lancet. 2020 22;395(10224):565-74.

14 Zhou P, Yang XL, Wang XG, Hu B, Zhang L, Zhang W, et al. A pneumonia outbreak associated with a new coronavirus of probable bat origin. Nature. 2020 Feb;579(7798)270, 3.

15 Phan T. Novel coronavirus: from discovery to clinical diagnostics. Infect Genet Evol. 2020 Apr;79:104211.

16 Lam TT-Y, Shum MH-H, Zhu H-C, Tong Y-G, Ni X-B, Liao Y-S, et al. Identification of 2019-nCoV related coronaviruses in Malayan pangolins in southern China. bioRxiv. 2020 Feb;2020.02.13.945485.

17 Cyranoski D. Mystery deepens over animal source of coronavirus. Nature. 2020 Feb; 579(7797):18-9.

18 Li X, Zai J, Zhao Q, Nie Q, Li Y, Foley BT, et al. Evolutionary history, potential intermediate animal host, and cross-species analyses of SARS-CoV-2. J Med Virol. 2020 Feb.

$19 \mathrm{Lu}$ R, Zhao X, Li J, Niu P, Yang B, Wu H, et al. Genomic characterisation and epidemiology of 2019 novel coronavirus: implications for virus origins and receptor binding. Lancet. 2020 Feb;395(10224):565-74.

20 Wu A, Peng Y, Huang B, Ding X, Wang X, Niu $P$, et al. Genome composition and divergence of the novel coronavirus (2019-nCoV) originating in China. Cell Host Microbe. 2020 Feb;27(3):325, 8 .

21 Hoffmann M, Kleine-Weber H, Schroeder S, Krüger N, Herrler T, Erichsen S, et al. SARSCoV-2 cell entry depends on ACE2 and TMPRSS2 and is blocked by a clinically proven protease inhibitor. Cell. 2020 Mar;

22 Yan R, Zhang Y, Li Y, Xia L, Guo Y, Zhou Q. Structural basis for the recognition of the SARS-CoV-2 by full-length human ACE2. Science. 2020 Mar.

23 Liu Z, Xiao X, Wei X, Li J, Yang J, Tan H, et al. Composition and divergence of coronavirus spike proteins and host ACE2 receptors predict potential intermediate hosts of SARSCoV-2. J Med Virol. 2020 Feb.

24 Wrapp D, Wang N, Corbett KS, Goldsmith JA, Hsieh CL, Abiona O, et al. Cryo-EM structure of the 2019-nCoV spike in the prefusion conformation. Science. 2020 Feb;367(6483):1260, 3.
25 Ye M, Wysocki J, William J, Soler MJ, Cokic I, Batlle D. Glomerular localization and expression of angiotensin-converting enzyme 2 and angiotensin-converting enzyme: implications for albuminuria in diabetes. J Am Soc Nephrol. 2006 Nov; 17(11):3067-75.

26 Zumla A, Chan JF, Azhar EI, Hui DS, Yuen KY. Coronaviruses - drug discovery and therapeutic options. Nat Rev Drug Discov. 2016; 15(5):327-47.

27 Vincent MJ, Bergeron E, Benjannet S, Erickson BR, Rollin PE, Ksiazek TG, et al. Chloroquine is a potent inhibitor of SARS coronavirus infection and spread. Virol J. 2005 Aug; 2(1):69.

28 Stadler K, Ha HR, Ciminale V, Spirli C, Saletti $\mathrm{G}$, Schiavon M, et al. Amiodarone alters late endosomes and inhibits SARS coronavirus infection at a post-endosomal level. Am J Respir Cell Mol Biol. 2008 Aug;39(2):142-9.

29 Wan Y, Shang J, Graham R, Baric RS, Li F. Receptor recognition by the novel coronavirus from wuhan: an analysis based on decade-long structural studies of SARS coronavirus. J Virol. 2020 Jan;94(7). doi: 10.1128/JVI.00127-20

30 Kruse RL. Therapeutic strategies in an outbreak scenario to treat the novel coronavirus originating in Wuhan, China. F1000Res. 2020 Feb;9:72.

31 Cai G. Bulk and Single-Cell Transcriptomics Identify Tobacco-Use Disparity in Lung Gene Expression of ACE2, the Receptor of 2019nCov. Preprints. 2020;2020020051. doi: 10.20944/preprints202002.0051.v2.

32 Chu KH, Tsang WK, Tang CS, Lam MF, Lai $\mathrm{FM}$, To KF, et al. Acute renal impairment in coronavirus-associated severe acute respiratory syndrome. Kidney Int. $2005 \mathrm{Feb} ; 67(2)$ : 698-705.

33 Tisoncik JR, Korth MJ, Simmons CP, Farrar J, Martin TR, Katze MG. Into the eye of the cytokine storm. Microbiology and Molecular Biology Reviews:Microbiol Mol Biol Rev. 2012 Mar;76(1):16, 32.

34 Huang KJ, Su IJ, Theron M, Wu YC, Lai SK, Liu CC, et al. An interferon-gamma-related cytokine storm in SARS patients. J Med Virol. 2005 Feb; 75(2):185-94.

35 Perazella MA, Shirali AC. Nephrotoxicity of cancer immunotherapies: past, present and future. J Am Soc Nephrol. 2018 Aug;29(8): 2039-52. 
36 Moicean AD, Popp AM, Sinescu I. Thymoglobulin-new approaches to optimal outcomes. J Med Life. 2009;2(3):319-24.

37 Diao B, Feng Z, Wang C, Wang H, Liu L, Wang $\mathrm{C}$, et al. Human kidney is a target for novel severe acute respiratory syndrome coronavirus 2 (SARS-CoV-2) infection. medRxiv. 2020 Mar;2020.03.04.20031120.

38 Xu D, Zhang H, Gong H, Chen J, Ye J, Meng $\mathrm{T}$, et al. Identification of a Potential Mechanism of Acute Kidney Injury During the Covid-19 Outbreak: A Study Based on SingleCell Transcriptome Analysis. Preprints. 2020 Feb. Available from: https://www.preprints. org/manuscript/202002.0331/v1.

39 Volunteers A-2019-nCoV, Li Z, Wu M, Guo J, Yao J, Liao X, et al. Caution on kidney dysfunctions of 2019-nCoV patients. medRxiv. $2020 \mathrm{Feb} ; 2020.02 .08 .20021212$.

40 Cheng Y, Luo R, Wang K, Zhang M, Wang Z, Dong L, et al. Kidney impairment is associated with in-hospital death of COVID-19 patients. medRxiv. 2020 Feb;2020.02.18. 20023242.

41 Liu R, Miller J. China approves use of Roche drug in battle against coronavirus complications. Reuters. 2020 Mar [cited 2020 Mar 11]. Available from: https://www.reuters.com/article/us-health-coronavirus-china-rochehldg-idUSKBN20R0LF.

42 Jones G, Panova E. New insights and longterm safety of tocilizumab in rheumatoid arthritis. Ther Adv Musculoskelet Dis. 2018 Oct;10(10):195-9.

43 Gallagher PE, Ferrario CM, Tallant EA. Regulation of ACE2 in cardiac myocytes and fibroblasts. Am J Physiol Heart Circ Physiol. 2008 Dec;295(6):H2373-9.

44 Oudit GY, Kassiri Z, Jiang C, Liu PP, Poutanen SM, Penninger JM, et al. SARS-coronavirus modulation of myocardial ACE2 expression and inflammation in patients with SARS. Eur J Clin Invest. 2009 Jul;39(7):61825.

45 Zheng YY, Ma YT, Zhang JY, Xie X. COVID-19 and the cardiovascular system. Nat Rev Cardiol. 2020 Mar;

46 Hashimoto T, Perlot T, Rehman A, Trichereau J, Ishiguro $\mathrm{H}$, Paolino $\mathrm{M}$, et al. ACE2 links amino acid malnutrition to microbial ecology and intestinal inflammation. Nature. $2012 \mathrm{Jul}$; 487(7408):477-81.

47 Yeo C, Kaushal S, Yeo D. Enteric involvement of coronaviruses: is faecal-oral transmission of SARS-CoV-2 possible? Lancet Gastroenterol Hepatol. 2020 Feb;5(4):335, 7.
48 Remuzzi A, Remuzzi G. COVID-19 and Italy: what next? Lancet. 2020 Mar. doi:

49 Jessup JA, Gallagher PE, Averill DB, Brosnihan KB, Tallant EA, Chappell MC, et al. Effect of angiotensin II blockade on a new congenic model of hypertension derived from transgenic Ren-2 rats. Am J Physiol Heart Circ Physiol. 2006 Nov;291(5):H2166-72.

50 Ferrario CM, Jessup J, Chappell MC, Averill DB, Brosnihan KB, Tallant EA, et al. Effect of angiotensin-converting enzyme inhibition and angiotensin II receptor blockers on cardiac angiotensin-converting enzyme 2. Circulation. 2005 May;111(20):2605-10.

51 Ishiyama Y, Gallagher PE, Averill DB, Tallant EA, Brosnihan KB, Ferrario CM. Upregulation of angiotensin-converting enzyme 2 after myocardial infarction by blockade of angiotensin II receptors. Hypertension. 2004 May; 43(5):970-6.

52 Gallagher PE, Ferrario CM, Tallant EA. MAP kinase/phosphatase pathway mediates the regulation of ACE2 by angiotensin peptides. Am J Physiol Cell Physiol 2008 Nov;295(5): C1169-74.

53 Fang L, Karakiulakis G, Roth M. Are patients with hypertension and diabetes mellitus at increased risk for COVID-19 infection? Lancet Respir Med. 2020 Mar.

54 Zou Z, Yan Y, Shu Y, Gao R, Sun Y, Li X, et al. Angiotensin-converting enzyme 2 protects from lethal avian influenza A H5N1 infections. Nat Commun. 2014 May;5(1):3594-7.

55 Ye R, Liu Z. ACE2 exhibits protective effects against LPS-induced acute lung injury in mice by inhibiting the LPS-TLR4 pathway. Exp Mol Pathol. 2020 Apr;113:104350.

56 Kuba K, Imai Y, Rao S, Gao H, Guo F, Guan $B$, et al. A crucial role of angiotensin converting enzyme 2 (ACE2) in SARS coronavirusinduced lung injury. Nat Med. 2005 Aug; 11(8):875-9.

57 Gu H, Xie Z, Li T, Zhang S, Lai C, Zhu P, et al. Angiotensin-converting enzyme 2 inhibits lung injury induced by respiratory syncytial virus. Sci Rep. 2016 Jan;6:19840.

58 Towler P, Staker B, Prasad SG, Menon S, Tang J, Parsons T, et al. ACE2 X-ray structures reveal a large hinge-bending motion important for inhibitor binding and catalysis. J Biol Chem. 2004 Apr;279(17):17996-8007.
59 Ye R, Liu Z. ACE2 exhibits protective effects against LPS-induced acute lung injury in mice by inhibiting the LPS-TLR4 pathway. Exp Mol Pathol. 2019 Dec;113:104350.

60 Imai Y, Kuba K, Rao S, Huan Y, Guo F, Guan $\mathrm{B}$, et al. Angiotensin-converting enzyme 2 protects from severe acute lung failure. $\mathrm{Na}-$ ture. 2005 Jul;436(7047):112-6.

61 ESH Statement on COVID-19| European Society of Hypertension [Internet]. [cited 2020 Mar 13]. Available from: https://www.eshonline.org/spotlights/esh-statement-on-covid-19/

62 Position Statement of the ESC Council on Hypertension on ACE-Inhibitors and Angiotensin Receptor Blockers [Internet]. [cited 2020 Mar 16]. Available from: https://www.escardio.org/Councils/Council-on-Hypertension(CHT)/News/position-statement-of-the-esccouncil-on-hypertension-on-ace-inhibitorsand-ang

63 Fedson DS, Jacobson JR, Rordam OM, Opal SM. Treating the host response to Ebola virus disease with generic statins and angiotensin receptor blockers. mBio. 2015 Jul;6(3): e00716.

64 Use of angiotensin receptor blockers such as Telmisartan, Losartsan in nCoV Wuhan Corona Virus infections - Novel mode of treatment. 2020 Mar [cited 2020 Mar 13]. Available from: https://www.bmj.com/content/368/bmj.m406/rr-2

65 Ma Y, Diao B, Lv X, Zhu J, Liang W, Liu L, et al. 2019 novel coronavirus disease in hemodialysis (HD) patients: report from one $\mathrm{HD}$ center in Wuhan, China. medRxiv. 2020 Feb; 2020.02.24.20027201.

66 CDC. Coronavirus Disease 2019 (COVID-19) [Internet]. Centers for Disease Control and Prevention. 2020 Feb [cited 2020 Mar 12]. Available from: https://www.cdc.gov/ coronavirus/2019-ncov/infection-control/ control-recommendations.html

67 Naicker S, Yang C-W, Hwang S-J, Liu B-C, Chen J-H, Jha V. The novel coronavirus 2019 epidemic and kidneys. Kidney Int. 2020 Mar. doi: 10.1016/j.kint.2020.03.001.

68 Gulnik S, Erickson JW, Xie D. HIV protease: enzyme function and drug resistance. Vitam Horm. 2000;58:213-56.

69 Yao XH, Li TY, He ZC, et al. A pathological report of three COVID-19 cases by minimally invasive autopsies. Zhonghua Bing Li Xue Za Zhi. 2020. doi: 10.3760/cma.j.cn11215120200312-00193. 32172546 